\title{
Author Spotlight: Maria Cristina Ripoli
}

\section{Maria Cristina Ripoli ${ }^{1}$}

Accepted: 3 September 2020 / Published online: 21 September 2020

(c) Springer Science+Business Media, LLC, part of Springer Nature 2020

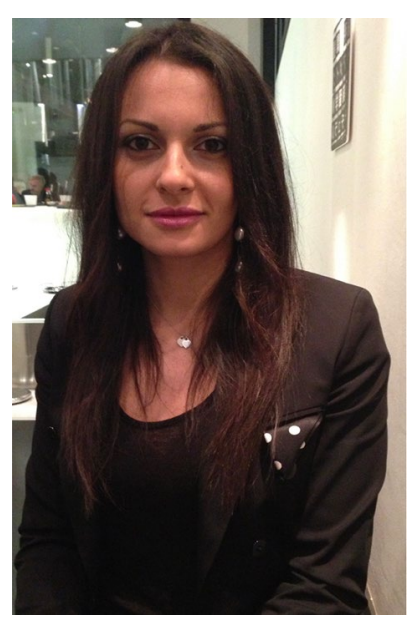

Maria Cristina Ripoli is a MD graduated at the University of Bologna-Alma Mater Studiorum-in 2012 and specialized in general surgery in July 2018 at St. Orsola University Hospital in Bologna.
She is interested in the study and surgical treatment of digestive diseases and cancer, and she is also involved in the treatment of trauma patients. She is an ATLS instructor.

Publisher's Note Springer Nature remains neutral with regard to jurisdictional claims in published maps and institutional affiliations.

Maria Cristina Ripoli

cristina_ri@hotmail.it

1 Bologna, Italy 